\title{
Quality of life and duration of hemodialysis in patients with chronic kidney disease (CKD): a cross-sectional study
}

\author{
Qualidade de vida e tempo de hemodiálise em pacientes \\ com doença renal crônica (DRC): um estudo transversal
}

\author{
Jefferson Belarmino Nunes Barbosa, Elaine Cristina Santa Cruz de Moura, \\ Celine Lorena Oliveira Barboza de Lira, Patrícia Érika de Melo Marinho*
}

Universidade Federal de Pernambuco (UFPE), Recife, PE, Brazil

\begin{abstract}
Introduction: Quality of life (QoL) of hemodialysis patients is a major evaluative marker currently measured, while treatment time is a clinical determinant associated with impaired QOL. Objective: To evaluate QOL in individuals undergoing hemodialysis (HD) considering treatment time and the presence of comorbidities. Methods: A cross-sectional study conducted in the hemodialysis unit of the Hospital das Clínicas da Universidade Federal de Pernambuco (HC-UFPE). We studied patients with Chronic Kidney Disease (CKD) of both genders over the age of 18 years, at any level of education and undergoing HD for at least 6 months. We evaluated the demographic/socioeconomic and clinical data, followed by application of the quality of life questionnaire (KDQOL-SF). Results: Participants were 47 patients with a mean age of $50.94 \pm 13.33$ years, $55.3 \%$ were male and average treatment time of $57.35 \pm 61.46$ months. Hypertension $(59.6 \%)$ was the most frequent underlying disease. According to the responses obtained through the KDQOL-SF, the situation at work and physical limitation scored worse. Sexual function (85.83) and encouragement by the team had the best performance. There were no differences in dimensions of questionnaire and treatment time. Conclusion: The presence of comorbidities and HD duration were not found to be possible factors for changing QoL in this study. However, we suggest that future studies evaluate other factors such as laboratory, emotional and functional data to check for changes in QoL in these patients related to HD duration.
\end{abstract}

Keywords: Chronic Renal Insufficiency. Renal Dialysis. Quality of life.

\footnotetext{
JBNB: Master student, e-mail: jb_nunes1987@yahoo.com.br ECSCM: BS, e-mail: elainecscm2@gmail.com CLOBL: BS, e-mail: celineblira@gmail.com

PEMM: PhD, e-mail: patmarinho@yahoo.com.br
} 
Resumo

Introdução: A qualidade de vida (QV) dos pacientes hemodialíticos é um dos principais marcadores avaliativos atualmente e o tempo de tratamento é um determinante clínico associado à QV prejudicada. Objetivo: Avaliar a QV em indivíduos submetidos à hemodiálise (HD) considerando o tempo de tratamento e a presença de comorbidades. Métodos: Estudo transversal desenvolvido no setor de hemodiálise do Hospital das Clínicas da Universidade Federal de Pernambuco (HC-UFPE), realizado em pacientes com Doença Renal Crônica (DRC) de ambos os sexos, maiores de 18 anos, em qualquer nível de escolaridade e em HD a pelo menos seis meses. Foram avaliados os dados demográfico/socioeconômico e clínico, seguidos da aplicação do questionário de QV (KDQOL-SF). Resultado: Participaram do estudo 47 pacientes, com média de idade de 50,94 $\pm 13,33$ anos, sendo 55,3\% do sexo masculino e média do tempo de tratamento de 57,35 $\pm 61,46$ meses. A Hipertensão Arterial Sistêmica (HAS) (59,6\%) foi a patologia de base mais frequente. De acordo com as respostas obtidas através do KDQOL-SF, a situação no trabalho e a limitação física apresentaram piores resultados. A função sexual $(85,83)$ e o encorajamento da equipe apresentaram o melhor desempenho. Não se observou diferenças no comportamento das dimensões do questionário com o tempo de tratamento. Conclusão: A presença de comorbidades e o tempo de HD não se apresentaram como possíveis fatores para alteração da QV em nosso estudo. No entanto, sugerimos que estudos futuros possam avaliar outros fatores como dados laboratoriais, emocionais e funcionais para verificar a existência de alterações na QV nesses pacientes relacionadas ao tempo de $H D$.

Palavras-chave: Insuficiência Renal Crônica. Diálise Renal. Qualidade de vida.

\section{Introduction}

Chronic Kidney Disease (CKD) is a clinical syndrome characterized by slow, progressive and irreversible loss in kidney function (1). With the increase in the aged population and in patients affected by Systemic Arterial Hypertension (SAH) and Diabetes Melittus (DM), the number of people with CKD has been increasing worldwide $(2,3)$.

In the terminal phase of CKD, hemodialysis (HD) is the most widely used renal replacement therapy throughout the world, contributing to increased patient survival (4). However, this procedure can cause loss of functional level with a consequent reduction in quality of life (QoL) over time (5). In addition, the absence of regular physical activity in this population may be associated with an appearance of comorbidities related to cardiovascular diseases, anemia, infections, hepatitis, bone diseases, and malnutrition, among others, favoring the risk of hospitalization and death (6).

Quality of life is defined by WHO as "the individual's perception of their position in life within the context of the culture and values systems in which they are inserted, and in relation to their goals, expectations, standards and concerns" (7). It is considered important for evaluation and follow-up of chronic patients submitted to intervention programs such as hemodialysis (8). In CKD patients undergoing HD, the main tool used to measure QOL is the Kidney Disease and Quality of Life Short Form (KDQOL-SF $\left.{ }^{\mathrm{TM}}\right)(9,10)$.

Treatment time is also a clinical determinant that when associated with factors such as advanced age, female gender, low level of schooling, unemployment and low income can affect QoL $(11,12)$. Some studies have not identified significant changes in QoL in relation to HD treatment time $(13,14)$. However, the presence of concomitant comorbidities presented a negative correlation with the QoL domains, justifying the reduced values evidenced by these patients, which improved in some domains one year after starting HD (15). Considering that the occurrence of comorbidities among patients undergoing HD may occur among those who are subjected to treatment for a longer period and that this condition may compromise their quality of life, evaluating the latter provides a way to verify the repercussion of the disease on the emotional, social, physical and labor aspects of these patients, and therefore measure how these dimensions can 
be modified after an intervention program. Thus, the objective of this study was to evaluate QoL through KDQOL-SF ${ }^{\mathrm{TM}}$ in subjects submitted to HD considering hemodialysis treatment time and the presence of comorbidities among them, and based on the hypothesis that longer hemodialysis duration and the presence of comorbidities lead to worse quality of life.

\section{Methods}

This is a cross-sectional study conducted from April to July 2014 in the Nephrology Service hemodialysis sector of the Hospital das Clínicas of the Universidade Federal de Pernambuco. The present study was approved by the Institutional Research Ethics Committee (CAAE: 26164913.1.0000.5208), according to Resolution 466/2012 of the National Health Council.

The study included patients with Terminal Chronic Kidney Disease (CKD) of both genders, over 18 years of age, at any education level, undergoing hemodialysis for at least 6 months and who were physically inactive. Those who presented cognitive deficit (assessed through the Mini-Mental State Examination MMSE) or changes that compromised their understanding and interpretation of the questions and/or hearing impairment were excluded.

\section{Procedures for data collection}

An evaluation of the patients' mental state was initially carried out the through MMSE. The classification adopted in the present study took into account the education level as: less than 15 points for illiterates; less than 22 points for education level between 1 and 11 years; and below 27 points for over 11 years of education reflecting the presence of cognitive deficit (16).

Next, demographic and socioeconomic data were evaluated (age, gender, marital status, education level, religion, current occupation, residence, family/ personal income), in addition to clinical data (weight, height and body mass index), CKD etiology, HD treatment duration (in months) and the number of comorbidities were also verified through medical records.

QoL was subsequently assessed using the KDQOL$\mathrm{SF}^{\mathrm{TM}}$. The first part of this instrument was composed of 36 items divided into 8 dimensions: physical functioning, role-physical, role-emotional, social functioning, mental health, bodily pain, vitality "energy/ fatigue" and perceptions on general health. The second part evaluates kidney disease, containing 11 dimensions: symptoms/problems, effects of renal disease, burden of CKD, occupational status, cognitive function, social interactions, sexual functioning, sleep, social support, health care staff support and patient satisfaction. In order to obtain the QoL score, the numerical values of each dimension were transformed into a score ranging from 0 to 100 in the studied dimension, where scores below 50 indicated reduced QoL and scores greater than 50 indicated better QoL (9).

\section{Data analysis}

Distribution of normality was initially performed by the Kolmogorov-Smirnov test for quantitative variables. Comparisons for the numerical variables were made using Student's t-test and Mann-Whitney test (age, weight, height, BMI, treatment time). Data were presented as mean \pm standard deviation or percentage. The comparison between hemodialysis treatment duration (in months) and each KDQOL-SF ${ }^{\mathrm{TM}}$ domain were performed using the Chi-Square Test and/or Fisher's Exact Test for categorical variables. Significant p-values lower than 0.05 were considered. All tests were applied with $95 \%$ confidence. The results were presented in tabular form with their respective absolute and relative frequencies. Median HD duration was used for comparison with all QoL questionnaire dimensions, clinical data, and the presence of comorbidities. The information was tabulated in Excel ${ }^{\circledR} 2007$ and later transferred to SPSS $^{\circledR}$ version 18.0.

\section{Results}

Of the 63 patients with terminal CKD (stage 5) enrolled and treated in the hemodialysis service, 16 were excluded ( 2 did not agree to participate in the study, 10 were undergoing treatment for less than 6 months, and 4 presented cognitive deficits), resulting in a total of 47 patients ( $74.6 \%$ of the total patients). The mean age was $50.94 \pm 13.33$ years and mean HD duration was $57.35 \pm 61.46$ months. (Table 1 )

Among the underlying diseases, SAH (59.6\%) was the most frequent, with the majority of patients $(83.0 \%)$ presenting between 0 and 1 comorbidity. 
The complete values regarding socio-demographic/ economic aspects, causes of renal disease and comorbidities are presented in Table 1 .

The dimensions burden of CKD, occupational status, physical functioning, general health, role-physical and role-emotional, as well as physical and mental composition presented reduced QoL (Table 2).

Table 1 - Sociodemographic characteristics, pathologies related to the development of CKD and comorbidities

\begin{tabular}{|c|c|c|c|c|}
\hline Variables & $\begin{array}{c}\text { Frequency } \\
(n=47)\end{array}$ & $\%$ & Mean & SD \\
\hline Age (years) & & & 50.94 & 13.33 \\
\hline $\begin{array}{l}\text { Hemodialysis } \\
\text { duration (months) }\end{array}$ & & & 57.35 & 61.46 \\
\hline BMI $\left(\mathbf{k g} / \mathrm{m}^{2}\right)$ & & & 24.20 & 4.78 \\
\hline \multicolumn{5}{|l|}{ Gender } \\
\hline Male & 26 & 55.3 & & \\
\hline Female & 21 & 44.7 & & \\
\hline \multicolumn{5}{|l|}{ Residence } \\
\hline (Others) & 15 & 31.9 & & \\
\hline \multicolumn{5}{|l|}{ Marital status } \\
\hline Has a partner & 27 & 57.4 & & \\
\hline $\begin{array}{l}\text { Does not have } \\
\text { a partner }\end{array}$ & 20 & 42.6 & & \\
\hline \multicolumn{5}{|l|}{ Ocupation } \\
\hline No & 33 & 70.2 & & \\
\hline Yes & 14 & 29.8 & & \\
\hline \multicolumn{5}{|l|}{ Reliqion } \\
\hline No & 8 & 17 & & \\
\hline Yes & 39 & 83 & & \\
\hline \multicolumn{5}{|l|}{ Home of your own } \\
\hline No & 12 & 25.5 & & \\
\hline Yes & 35 & 74.5 & & \\
\hline \multicolumn{5}{|l|}{ Schooling } \\
\hline Up to 1 year & 7 & 14.9 & & \\
\hline Above 1 year & 40 & 85.1 & & \\
\hline \multicolumn{5}{|l|}{ Family/ } \\
\hline $\begin{array}{r}\text { Personal Income } \\
\text { Below } 1 \mathrm{MW}\end{array}$ & 1 & 2.1 & & \\
\hline Above $1 \mathrm{MW}$ & 46 & 97.9 & & \\
\hline \multicolumn{5}{|l|}{ Aetiology of CKD } \\
\hline $\begin{array}{c}\text { DM (Yes) } \\
\text { (No) }\end{array}$ & $\begin{array}{l}18 \\
29\end{array}$ & $\begin{array}{l}38.3 \\
61.7\end{array}$ & & \\
\hline $\begin{array}{l}\text { KD (Yes) } \\
\text { (No) }\end{array}$ & $\begin{array}{c}5 \\
42\end{array}$ & $\begin{array}{l}10.6 \\
89.4\end{array}$ & & \\
\hline SAH (Yes) & 28 & 59.6 & & \\
\hline (No) & 19 & 40.4 & & \\
\hline
\end{tabular}

(To be continued)
(Conclusion)

Table 1 - Sociodemographic characteristics, pathologies related to the development of CKD and comorbidities

\begin{tabular}{lcccc}
\hline Variables & $\begin{array}{c}\text { Frequency } \\
(\mathrm{n}=47)\end{array}$ & $\%$ & Mean & SD \\
\hline \multicolumn{1}{c}{ OC (Yes) } & 26 & 56.3 & \\
$\quad($ No) & 21 & 44.7 & \\
\hline 0 or 1 comorbidity & 39 & 83.0 & \\
$\mathbf{2}$ or more & 8 & 17.0 & \\
comorbidities & & & \\
\hline
\end{tabular}

Note: CKD: chronic kidney disease; SD: standard deviation; HD Hemodialysis; MW - Minimum wage; SAH - Systemic Arterial Hypertension; DM - Diabetes Melittus; KD - Kidney Disease; OC Other Comorbidities.

Table 2 - Characteristics of the dimensions of the KDQOL questionnaire of patients submitted to HD

\begin{tabular}{lcc}
\hline Variables & Mean & SD \\
\hline Symptoms & 68.40 & 17.19 \\
Effects of kidney disease & 69.88 & 21.19 \\
Burden of kidney disease & 41.22 & 28.12 \\
Work status & 17.02 & 26.12 \\
Cognitive function & 80.14 & 21.56 \\
Quality of social interaction & 76.31 & 22.71 \\
Sexual function & 85.83 & 20.52 \\
Sleep & 68.51 & 27.13 \\
Social support & 81.21 & 28.58 \\
Dialysis staff encouragement & 82.45 & 23.98 \\
Global health & 67.23 & 32.42 \\
Patient satisfation & 76.95 & 25.19 \\
Physical functioning & 47.02 & 28.85 \\
Role of physical & 31.38 & 33.57 \\
Body pain & 66.91 & 29.97 \\
General health & 47.87 & 24.56 \\
Emotional well-being & 69.28 & 25.02 \\
Role of emotional & 45.39 & 36.40 \\
Social function & 69.68 & 33.25 \\
Energy/fatigue & 54.79 & 27.19 \\
SF-12 Physical composition & 38.46 & 9.11 \\
SF-12 Emotional composition & 46.70 & 11.74 \\
\hline
\end{tabular}

Note: SF - Short form.

No differences in the behavior of the questionnaire dimensions were observed after stratification for HD duration through the median (36 months) (Figure 1). 


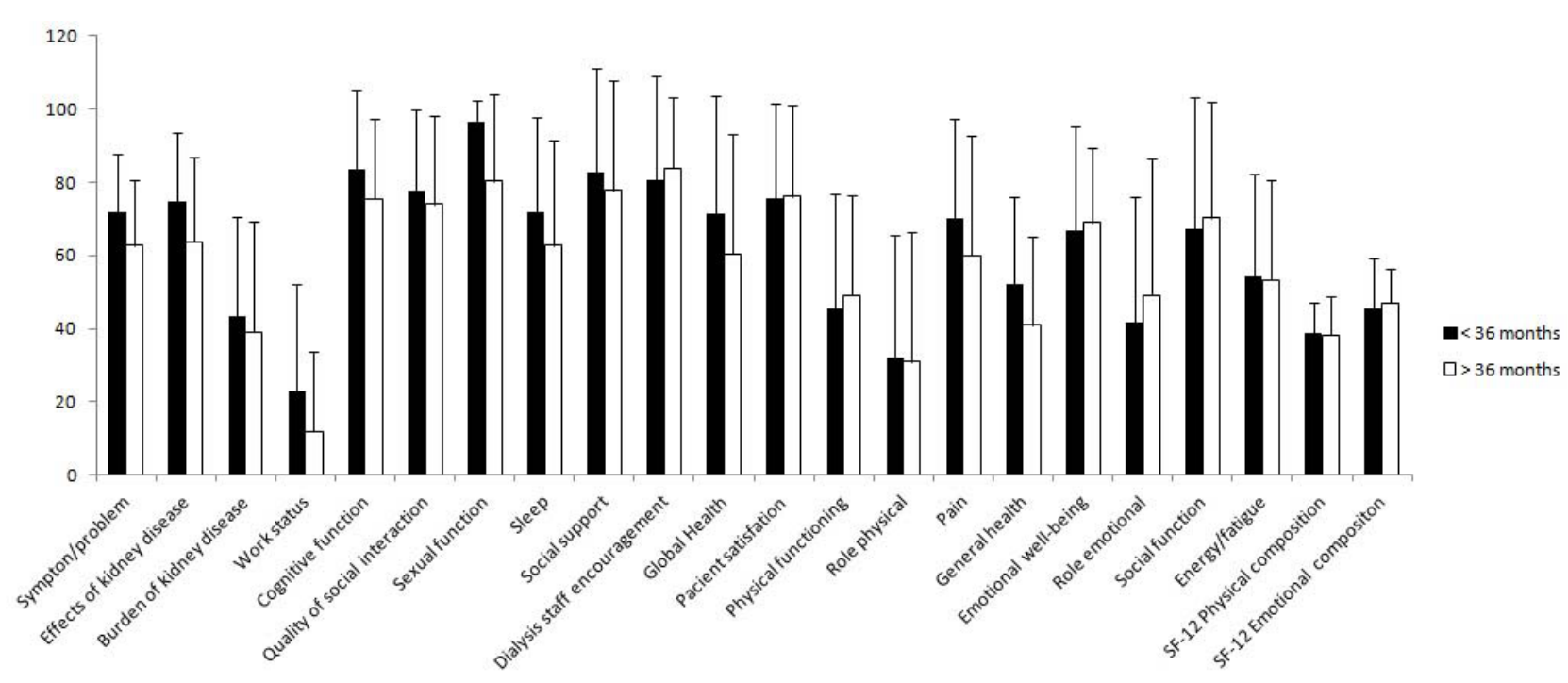

Figure 1 - Comparison of the median time with the dimensions of the KDQOL questionnaire.

\section{Discussion}

In this study, the quality of life dimensions affected by treatment time in hemodialysis patients were: burden of CKD, occupational status, physical functioning, general health, role-physical and role-emotional, and physical and mental composition. SAH was the most frequent cause of CKD, and HD treatment time and the presence of comorbidities did not interfere in the QoL dimensions between the groups.

QoL may be altered in patients undergoing HD, especially among different races, social relations, cultural diversity and ethnicities (17). Some studies report that it may also be associated with hemoglobin level, socioeconomic status, literacy, dialysis program, gender, comorbidities, depression and previous unsuccessful kidney transplant, as well as clinical manifestations of the disease, side effects, nutritional status and hospitalization $(18,19)$.

In analyzing the QoL of patients undergoing HD, physical functioning, physical function and burden of CKD dimensions seem to be related and dependent on physical health $(20,21)$. These dimensions are related to patient's constant complaints such as a lack of energy, feelings of discouragement and fatigue, which probably decrease the scores in these dimensions, possibly due to changes in their health condition related to the disease and to the treatment (22).

The physical function dimension of the KDQOL$\mathrm{SF}^{\mathrm{TM}}$ is composed of ten items that evaluate limitations in performing daily activities due to health condition, in self-care and for activities which demand a lot of effort (22), as it is one of the compromised dimensions among the patients evaluated in our study.

According to our results, physical limitation and occupational status were the most affected dimensions among the evaluated patients, being similar to other studies $(23,24)$. The physical limitation imposed by CKD and by the HD treatment duration may be a consequence of systemic alterations caused by the disease, especially those related to musculoskeletal disorders (25), in addition to factors such as dependence on medical support, having a strict treatment regimen, pain and suffering during the sessions, sleep disorders, immobility, machine dependence, specific diet and body image changes (17).

Regarding occupational status, our results are similar to other studies performed in Brazil and abroad $(26,27)$. One possible explanation would be patients' understanding regarding the activities they should be able to easily perform being in an economically more active population group; however, their activities are interrupted the CKD (28), thus preventing them from earning (29). Therefore, treatment alone or in association with physical symptoms may contribute to perception of disease burden on patients (29).

Our results indicated a low number of comorbidities among patients, unlike other studies $(1,30)$. The presence of comorbidities is an important predictor of mortality (31). The studies indicate reduced QoL (32) for patients with CKD associated to cardiovascular disease. 
Regarding HD duration, there were also no differences observed between those who were below or above 36 months of treatment. Some studies also found no changes $(11,33,34)$, which makes us think of the possibility of other factors occurring besides those investigated here, which could be contributing to these results. Thus, the present study recognizes that inclusion of laboratorial factors (urea, creatinine, PTH (ParaThyroid Hormone)), emotional factors (depression and anxiety), functional factors (evaluation of activities of daily living and work) and the analysis of hemodialysis efficiency (Kt/V) are limiting factors that need to be introduced to verify its association with QoL in future studies. Another aspect to be considered concerns the sample consisting only of patients coming from a high complexity hospital. This point needs to be taken into account, considering that patients' characteristics (greater presence of comorbidities and longer treatment time on hemodialysis) may not reflect the reality of other hemodialysis treatment centers. In this sense, an investigation on quality of life needs to be conducted in these places, so that the size of these changes can be evaluated in these patients.

Repercussions of the decline in the quality of life of chronic patients constitute a challenge for health professionals, especially those who deal with the limitations imposed by the disease itself or its evolution. As professionals who are attentive to the physical and functional issues of the chronic renal patient and aware of the importance of evaluating the quality of life of these patients, physiotherapists need to seek therapeutic strategies that optimize functional independence and autonomy, thus minimizing the adverse consequences of the disease on quality of life.

\section{Conclusion}

Our results have pointed to a reduction in the following dimensions of burden of CKD, occupational status, physical functioning, general health, rolephysical and role-emotional, as well as the physical and mental composition of quality of life. Regarding the presence of comorbidities, SAH was the main comorbidity found. HD treatment duration and the presence of comorbidities were not evidenced as possible factors for QoL changes in our study. Therefore, we suggest that future studies include other factors such as evaluating kidney function through laboratory data, thus verifying concomitant presence of depressive and/or anxiety symptoms in these patients, and evaluating hemodialysis efficiency in order to verify the existence of association between these and QoL related to hemodialysis duration.

\section{References}

1. Ting GO, Kjellstrand C, Freitas T, Carrie BJ, Zarghamee S. Long-Term Study of High-Comorbidity ESRD Patients Converted From Conventional to Short Daily Hemodialysis. Am J Kidney Dis. 2003;42(5):1020-35.

2. Bakris GL, Sowers JR. ASH Position Paper: Treatment of Hypertension in Patients With Diabetes - An Update. J Clin Hypertens. 2008;10(9):707-13.

3. Kurella M, Chertow GM, Fried LF, Cummings SR, Harris T, Simonsick E, et al. Chronic kidney disease and cognitive impairment in the elderly: The Health, Aging, and Body Composition study. J Am Soc Nephrol. 2005;16(7):2127-33.

4. Sociedade Brasileira de Nefrologia - SBN. Censo Geral 2011 [cited 2015 Mar 31]. Available from: https:// tinyurl.com/lf4scbk.

5. Jassal SV, Watson D. Dialysis in late life: benefit or burden. Clin J Am Soc Nephrol. 2009;4(12):2008-12.

6. Thomas R, Kanso A, Sedor JR. Chronic Kidney Disease and Its Complications. Prim Care. 2008;35(2):329-44.

7. WHOQOL Group. The World Health Organization Quality of Life Assessment (WHOQOL): Position paper from the World Health Organization. Soc Sci Med. 1995;41(10):1403-9.

8. Campolina AG, Bortoluzzo AB, Ferraz MB, Ciconelli RM. Validação da versão brasileira do questionário genérico de qualidade de vida short-form 6 dimensions (SF-6D Brasil). Cien Saude Colet. 2011;16(7):3103-10.

9. Duarte PS, Miyazaki MCOS, Ciconelli RM, Sesso R. Tradução e adaptação cultural do instrumento de avaliação de qualidade de vida para pacientes renais crônicos (KDQOL-SFTM). Rev Assoc Med Bras. 2003;49(4):375-81. 
10. Moureia CA, Garletti Jr W, Lima LF, Lima CR, Ribeiro JF, Miranda AF. Avaliação das propriedades psicométricas básicas para a versão em português do KDQOL-SFTM. Rev Assoc Med Bras. 2009;55(1):22-8.

11. Tjaden LA, Vogelzang J, Jager KJ, van Stralen KJ, Maurice-Stam $\mathrm{H}$, Grootenhuis MA, et al. Long-term quality of life and social outcome of childhood end-stage renal disease. J Pediatr. 2014;165(2);336-42.

12. Unruh ML, Newman AB, Larive B, Dew MA, Miskulin DC, Greene T, et al. The influence of age on changes in health-related quality of life over three years in a cohort undergoing hemodialysis. J Am Geriatr Soc. 2008;56(9):1608-17.

13. Gabbay E, Meyer KB, Griffith JL, Richardson MM, Miskulin DC. Temporal Trends in Health-Related Quality of Life among Hemodialysis Patients in the United States. Clin J Am Soc Nephrol. 2010;5(2):261-7.

14. Feroze U, Noori N, Kovesdy CP, Molnar MZ, Martin DJ, Reina-Patton A, et al. Quality-of-life and mortality in hemodialysis patients: roles of race and nutritional status. Clin J Am Soc Nephrol. 2011;6(5):1100-11.

15. Stajonovic M, Ilic S, Stefanovic V. Influence of co-morbidity on health-related quality of life in patients treated with hemodialysis. Int J Artif Organs. 2006;29(11):1053-61.

16. Lourenço RA, Veras RP. Mini-Exame do Estado Mental: características psicométricas em idosos ambulatoriais. Rev Saúde Públ. 2006;40(4):712-9.

17. Anees M, Malik MR, Abbasi T, Nasir Z, Hussain Y, Ibrahim M. Demographic factors affecting quality of life of hemodialysis patients. Pak J Med Sci. 2014;30(5)1123-7.

18. Soni RK, Weisbord SD, Unruh ML. Health-related quality of life outcomes in chronic kidney disease. Cur Opin Nephrol Hypertens. 2010;19(2):153-9.

19. Ikizler TA. Nutrition Support for the Chronically Wasted or Acutely Catabolic Chronic Kidney Disease Patient. Semin Nephrol. 2009;29(1):75-84.

20. Johansen KL. Exercise and Chronic Kidney Disease. Sports Med. 2005;35(6):485-99.
21. Lessan-Pezeshki M, Rostami Z. Contributing Factors in Health-Related Quality of Life Assessment of ESRD Patients: A Single Center Study. Int J Nephrol Urol, 2009;1(2):129-36.

22. Kutner NG, Jassal SV. Quality of life and rehabilitation of elderly dialysis patients. Semin Dial. 2002;15(2):107-12.

23. Cruz MC, Andrade C, Urrutia M, Draibe S, Martins LAN, Sesso RCC. Quality of life in patients with chronic kidney disease. Clinics.2011;66(6):991-5.

24. Spiegel B, Melmed G, Robbins S, Esrailian E. Biomarkers and Health-Related Quality of Life in End-Stage Renal Disease: A Systematic Review. Clin J Am Soc Nephrol. 2008;3(6):1759-68.

25. Stavrianou K, Pallikarakis N. Quality of life of endstage renal disease patients and study on the implementation of nocturnal home hemodialysis in Greece. Hemodial Int. 2007;11(2):204-9

26. Devins GM, Mandin H, Hons RB, Burgess LD, Klassen J, Taub K, et al. Illness Intrusiveness and Quality of Life in End-Stage Renal Disease: Comparison and Stability Across Treatment Modalities. Health Psychol. 1990;9(2):117-42.

27. Lopes JM, Fukushima RLM, Inouye K, Pavarini SCI, Orlandi FS. Qualidade de vida relacionada à saúde de pacientes renais crônicos em diálise. Acta Paul Enferm. 2014;27(3):230-6.

28. Parvan K, Lakdizaji S, Roshangar F, Mostofi M. Quality of sleep and its relationship to quality of life in hemodialysis patients. J Caring Sci. 2013;2(4):295-304.

29. Orlić L, Matić-Glazar D, Martinović BS, Vlahović A. Work capacity in patients on hemodialysis. Acta Med Croatica. 2004;58(1):67-71.

30. Lopes AA, Bragg-Gresham JL, Goodkin DA, Fukuhara S, Mapes DL, Young EW, et al. Factors associated with health-related quality of life among hemodialysis patients in the DOPPS. Qual Life Res. 2007;16(4):545-57. 
31. Lin Y, Wu P, Kuo M, Lin M, Lee T, Chiu Y, et al. High Cost and Low Survival Rate in High Comorbidity Incident Elderly Hemodialysis Patients. Plos One. 2013;8(9):1-8.

32. Valderrábano F, Jofre R, López-Gómez JM. Quality of life in end-stage renal disease patients. Am J Kidney Dis. 2001;38(3):443-64.

33. Santos PR, Pontes LRSK. Mudança do nível de qualidade de vida em portadores de insuficiência renal crônica terminal durante seguimento de 12 meses. Rev Assoc Med Bras. 2007;53(4):329-34.
34. Cassileth BR, Lusk EJ, Strouse TB, Miller DS, Brown LL, Cross PA, et al. Psychosocial Status in Chronic Illness - A Comparative Analysis of Six Diagnostic Groups. N Engl J Med. 1984;311(8):506-11.

Received in $12 / 10 / 2016$ Recebido em 10/12/2016

Approved in 03/27/2017 Aprovado em 27/03/2017 